\title{
Clinical Utility of PALM-COEIN Classification for Abnormal Uterine Bleeding
}

\author{
Gunasena GGA' ${ }^{\mathrm{a}}$, Jayasundara DMCS ${ }^{\mathrm{b}}$ \\ Key words: PALM-COEIN classification system, abnormal uterine bleeding
}

\section{INTRODUCTION}

Abnormal uterine bleeding (AUB) may be defined as any variation from the normal menstrual cycle which includes changes in regularity and frequency of menses, duration of flow, or amount of blood $\operatorname{loss}^{1}$. Abnormal uterine bleeding affects up to $30 \%$ of women throughout their reproductive lifetime ${ }^{2}$. These disorders may significantly affect quality of life, result in time off work, lead to surgical intervention including hysterectomy and ultimately have a significant impact on the health care system itself ${ }^{3}$.

The investigation and management of AUB has been hampered by the confusing and inconsistently applied nomenclature. There is also a paucity of standardized methods for investigation and categorization of the potential causes ${ }^{4}$. The research in the field of AUB is also complicated by invariably applied nomenclature and non-standardized investigation methods; thus it is difficult to compare studies by different researchers. Therefore, it is essential to have a standardized universal terminology and a classification of potential etiologies for AUB to improve communication among practitioners and to guide research and education on this topic.

Beginning with workshops in 2005, with the involvement of contributors from

${ }^{a}$ Consultant Obstetrician and Gynaecologist District Base Hospital, Rikillagaskada, Sri Lanka

${ }^{b}$ Senior Lecturer in Obstetrics and Gynaecology, Faculty of Medicine, University of Colombo

Correspondence: Dr. G.G.A. Gunasena MBBS, $M D, M R C O G$,

Email: asankagunasena@gmail.com (D) http://orcid.org/0000-0003-2014-1292

Competing interests:The authors report no conflict of interest more than 17 countries on 6 continents, the International Federation of Gynaecology and Obstetrics (FIGO) proposed a new system for the classification of AUB in 2011. This classification system is known by the acronym PALM-COEIN ${ }^{5}$. The basic system comprises 9 categories: The first 4 are defined by visually objective structural criteria PALM (Polyp, Adenomyosis, Leiomyoma, Malignancy and hyperplasia); a second 4 that are unrelated to structural anomalies COEI (Coagulopathy, Ovulatory dysfunction, Endometrial and Iatrogenic), and a final category reserved for entities that are not yet classified (N). The American College of Obstetricians and Gynecologists adopted it in $2012^{6}$. Subsequently, many publications, recommendations and guidelines started using the PALM-COEIN classification in their methodology. Journal editors and editorial boards were encouraged to request the authors to prepare their manuscripts dealing with AUB in accordance with the PALMCOEIN classification.

We have more than 90-year experience in the universal nomenclature and classification systems introduced by FIGO, particularly in the field of gynaecological malignancies. These systems are practical, universally accepted, and aid clinicians and investigators in the guidance of research, treatment, and prognostication. But it is uncertain whether PALM-COEIN classification system has gained the same popularity among researchers or has been adopted by majority of clinicians even after six years of its introduction. Some clinicians may find the new terminology and classification difficult in their day to day clinical practice and may not use it routinely. If that is the case, there is a risk that the PALM-COEIN terminology and classification may have the same fate as the pelvic organ prolapse quantification classification. Although it was a good classification system which quantified the genital prolapse accurately, it hasn't gained much popularity among researchers and clinicians.

This review is an attempt to present the PALM-COEIN classification for AUB and critically appraise its clinical utility.

\section{NEW TERMINOLOGY - ADOPTED IN THE PALM COEIN CLASSIFICATION}

\section{NEW TERMINOLOGY - ACUTE AND CHRONIC AUB}

Available classifications used before the PALM-COEIN did not make a distinction between acute and chronic AUB in nonpregnant women. Instead, patient's clinical condition (e.g. hemodynamically unstable, shocked, or seriously anemic) was used in the description of patients.

The PALM-COEIN defines acute AUB as an episode of heavy bleeding that is of sufficient quantity to require immediate intervention to prevent further blood loss. Acute AUB may present in the background of existing chronic AUB or might occur without such a history. By contrast, chronic AUB is defined as bleeding from the uterine corpus that is abnormal in volume, regularity, and/or timing, and has been present for the majority of the past 6 months. Chronic AUB does not necessarily require immediate intervention ${ }^{5}$. The terms acute AUB and chronic AUB clearly and shortly describes the clinical condition of the patient and guide further management.

\section{"INTERMENSTRUAL BLEEDING" - TO REPLACE "METRORRHAGIA"}

Intermenstrual bleeding (IMB) occurs between clearly defined cyclic and predictable menses. Such bleeding may occur at random times or may manifest in a predictable manner at the same day in each 
cycle $^{5}$. The term IMB is clinically more sensible and appropriate and it is supposed to replace the word metrorrhagia.

\section{ABANDON THE TERM "DUB" - FIND OUT THE EXACT ETIOLOGY}

The term dysfunctional uterine bleeding (DUB) which was previously used as a diagnosis when there was no systemic or locally definable structural cause for AUB, is not included in the system. It was suggested during the agreement process that the term "DUB" should be abandoned ${ }^{7}$. In fact, the women who are classified as DUB actually have one or more of coagulopathy, disorders of ovulation, or primary endometrial disorder which are clearly described in the new classification system. Frequently, these etiologies tend to be missing in the list of differential diagnosis. The omission of the term DUB will alert the clinician about the potential of one of the above conditions being the culprit.

"HEAVY MENSTRUAL
BLEEDING" TO REPLACE
"MENORRHAGIA" - IS IT
REALLY NECESSARY?

The term menorrhagia is replaced by the term heavy menstrual bleeding (HMB). Excessive bleeding occurring with regular menstrual cycles (predictable bleeding) is called menorrhagia and this term was in use for generations. It is doubtful whether the term menorrhagia has created any confusion among the clinicians which would be rectified by the term HMB.

\section{PALM-COEIN FIGO CLASSIFICATION FOR AUB}

There are 9 main categories, which are arranged according to the acronym PALMCOEIN (Table 01). The components of the PALM group are discrete (structural) entities that can be measured visually with imaging techniques and/or histopathology, whereas the COEIN group is related to entities that are not defined by imaging or histopathology (non-structural) ${ }^{8}$. Each basic category was designed to include sub-classification systems, as necessary. The basic categories are expected to be used at primary care level whereas subclassifications would be most relevant at specialist and research levels.

Table 3.The limits of agreement between the hemoglobin and hematocrit Table 01: PALM-COEIN Classification of AUB

\begin{tabular}{|l|l|}
\hline Structural causes (PALM) & Non-structural causes (COEIN) \\
\hline Polyps & Coagulopathy \\
\hline Adenomyosis & Ovulatory dysfunction \\
\hline $\begin{array}{l}\text { Leiomyomas } \\
\text { - Submucosal } \\
\text { - Other }\end{array}$ & $\begin{array}{l}\text { Endometrial } \\
\text { (primary disorder of mechanisms regulating } \\
\text { Malignancy and hyperplasia }\end{array}$ \\
& local endometrial "hemostasis") \\
\cline { 2 - 2 } & Iatrogenic \\
\cline { 2 - 2 } & Not yet specified \\
\hline
\end{tabular}

\section{PALM-COEIN: EASY MNEMONIC TO REMEMBER}

It is obvious that this system has made remembering the causes of AUB easy since it is in the form of a mnemonic that uses common words palm and co(e)in, supplemented by pictures of a palm and a coin. Having a separate group (COEIN) for the non-structural causes of AUB highlights the importance of considering them as possible causative factors.

This system also recognizes the possibility of more than one pathology in an individual symptomatic woman. But caution should be taken with definable entities such as adenomyosis, leiomyomas, and endocervical / endometrial polyps as they are frequently asymptomatic and, therefore, not contributing to the presenting symptoms.

\section{LACK OF SUB- CLASSIFICATIONS FOR POLYPS AND ADENOMYOSIS}

Endometrial and endocervical polyps are indicated as AUB-P. There seems to be little controversy regarding the inclusion of polyps as they are often asymptomatic. Polyps have only a primary classification which indicates their presence or absence. A sub-classification including clinically relevant variables about polyps (location, size, number, morphology etc.) is not presented in the PALM-COEIN. Instead, clinicians are advised to include such information in their data collection systems.
Adenomyosis (AUB-A) is the second category in PALM group. The diagnostic criteria for adenomyosis vary substantially. The existing criteria are based on sonographic, magnetic resonance imaging (MRI)-based and histopathological findings. Recognizing women's limited access to MRI worldwide and the limited value of histopathological criteria in a clinical classification system, PALM-COEIN has correctly incorporated sonographic criteria as the minimum requirements for assigning the diagnosis of adenomyosis. Again a sub-classification is not presented in the PALM-COEIN for adenomyosis at least to indicate the distinctions between diffuse and focal (or multifocal) disease, which is also known as adenomyoma. The surgical management of adenomyoma is different from that of diffuse adenomyosis (e.g. wedge resection of adenomyoma).

\section{INFORMATIVE AND USEFUL SUB- CLASSIFICATION FOR LEIOMYOMA}

The term leiomyoma has been selected as the most accurate term to indicate the benign fibro-muscular tumors of uterus in the PALM-COEIN system (AUB-L). In addition to the primary classification system, which reflects only the presence or absence of one or more leiomyomas, there are also the secondary and tertiary classification systems (Table 02). In the secondary system, the leiomyomas involving the endometrial cavity (submucosal, marked as SM) must be distinguished from the others (marked 
Table 02: Leiomyoma sub-classification system (8).

\begin{tabular}{|c|c|c|}
\hline \multirow[t]{3}{*}{ SM-Submucosal } & 0 & Pedunculated intracavitary \\
\hline & 1 & $<50 \%$ intramural \\
\hline & 2 & $\geq 50 \%$ intramural \\
\hline \multirow[t]{6}{*}{ O - Other } & 3 & $\begin{array}{l}\text { Contacts endometrium, } 100 \% \\
\text { intramural }\end{array}$ \\
\hline & 4 & Intramural \\
\hline & 5 & Subserosal $\geq 50 \%$ intramural \\
\hline & 6 & Subserosal $<50 \%$ intramural \\
\hline & 7 & Subserosal pedunculated \\
\hline & 8 & Other (specify e.g. cervical, parasitic) \\
\hline \multirow[t]{2}{*}{$\begin{array}{l}\text { Hybrid leiomyomas } \\
\text { (impact both } \\
\text { endometrium and } \\
\text { serosa) }\end{array}$} & \multicolumn{2}{|c|}{$\begin{array}{l}\text { Two numbers are listed separated by a hyphen. By } \\
\text { convention, the first refers to the relationship with the } \\
\text { endometrium while the second refers to the relationship to } \\
\text { the serosa. One example is below }\end{array}$} \\
\hline & $2-5$ & $\begin{array}{l}\text { Submucosal and subserosal, each } \\
\text { with less than half the diameter in the } \\
\text { endometrial and peritoneal cavities, } \\
\text { respectively. }\end{array}$ \\
\hline
\end{tabular}

as $\mathrm{O}$ ), because sub-mucosal lesions are generally considered to be the most common contributors to the genesis of AUB. The tertiary classification system is a design for subendometrial or submucosal leiomyomas that was originally submitted by Wamsteker et al. ${ }^{9}$ and subsequently adopted by the European Society for Human Reproduction and Embriology (ESHRE).

Primary and secondary classifications of leiomyoma would be adequate in routine clinical practice whereas tertiary classification would be most useful for clinical investigators. It might be of use for clinicians who perform resectoscopic myomectomy.

\begin{tabular}{|l|}
\hline ENDOMETRIAL \\
HYPERPLASIA AND \\
MALIGNANCY IN THE \\
SAME CATEGORY (AUB-M) \\
- IS IT APPROPRIATE? \\
\hline
\end{tabular}

Both endometrial hyperplasia and malignancy are categorized as AUB-M in the PALM-COEIN classification. Further detailing should be done according to the WHO and FIGO classification and staging systems. It seems to be confusing to include endometrial hyperplasia without atypia in the same category with malignancy. consider coagulopathy in the differential diagnosis of women with $\mathrm{HMB}^{12}$ makes it necessary to have coagulopathy as a distinct category. Testing for coagulation disorders should be considered in women who have a history of heavy menstrual bleeding since menarche, personal history of abnormal bleeding (postpartum hemorrhage, surgical-related bleeding, bleeding associated with dental work, bruising or epistaxis 1-2 times per month) or family history of bleeding symptoms.

\begin{tabular}{l}
\hline NEED TO HAVE A SUB- \\
CLASSIFICATION \\
FOR OVULATORY \\
DYSFUNCTION (AUB-O) - \\
TO AVOID REPETITION \\
\hline
\end{tabular}

Ovulatory dysfunction (AUB-O) usually manifests as a combination of unpredictable timing of bleeding and variable amount of flow, which can result in HMB in some cases. Unexplained ovulatory disorders frequently occur at the extremes of reproductive age: adolescence and the menopause transition. Many cases of ovulatory dysfunction are secondary to endocrinopathies (e.g. polycystic ovary syndrome, thyroid diseases, hyperprolactinemia, adrenal gland diseases, and weight related disturbances such as obesity, anorexia, weight loss, and mental and physical stress experienced during extreme exercise associated with elite athletic training). In certain cases, the disorder may be iatrogenic, caused by gonadal steroids or drugs that impact dopamine metabolism, such as phenothiazines and tricyclic antidepressants. In the PALMCOEIN classification, these hormonal therapies and medications are also described in iatrogenic causes (AUB-I) and including the same causes under ovulatory dysfunction creates duplication within the classification system. To avoid this confusion, a sub-classification system should be introduced to AUB-O based on its cause; endocrinopathies, iatrogenic, unexplained etc. 


\begin{tabular}{|l|}
\hline DESPITE A VARIETY OF \\
ENDOMETRIAL CAUSES \\
FOR AUB; THE CATEGORY \\
"ENDOMETRIAL" \\
(AUB-E) INCLUDES \\
ONLY THE DISORDERS \\
OF ENDOMETRIAL \\
HAEMOSTASIS \\
\hline
\end{tabular}

Abnormal uterine bleeding could also be due to primary disorders of endometrium. High-quality evidence has demonstrated deficiencies in local production of vasoconstrictors such as endothelin-1 and prostaglandin $\mathrm{F} 2 \alpha$, and/or accelerated lysis of endometrial clot because of excessive production of plasminogen activator ${ }^{13}$. There is also evidence showing an increased local production of substances that promote vasodilation, e.g. prostaglandin E2 and prostacyclin ${ }^{12,14}$. Considering these facts, the PALM-COEIN classification has included primary disorders of local endometrial "haemostasis" in the category named Endometrial (AUB-E). The name "endometrial" for this category is a little confusing as well-known structural causes like endometrial hyperplasia (AUB-M) and endometrial polyps (AUB-P) are included in different categories though they originate from the endometrium. Endometrial inflammation or infection may also play a role in the genesis of AUB. Lesions like chronic endometritis are not rare in the histopathological diagnosis of endometrial sampling. However, chronic endometritis is not sub-classified citing lack of evidence to demonstrate a consistent relationship with the occurrence $\mathrm{AUB}^{15}$. Other rare associations like arterio-venous malformations and pelvic tuberculosis are also not included in this category due to lack of evidence. Therefore, AUB-E is concerned only with primary disorders of endometrial haemostasis which invariably becomes a diagnosis by exclusion of other identifiable abnormalities.

\section{MEDICATIONS ARE INCLUDED IN BOTH AUB-I AND AUB-O; DUPLICATION WITHIN THE SYSTEM}

The iatrogenic causes of AUB include medicated or inert intrauterine systems and pharmacologic agents that directly impact the endometrium, interfere with blood coagulation mechanisms, or influence the systemic control of ovulation ${ }^{1}$. Gonadal steroid therapy (estrogens, progestins, and androgens), levonorgestrel-releasing intrauterine system (LNG-IUS) and systemic agents that interfere with dopamine metabolism (antidepressants and antipsychotics) have the potential to cause AUB through interference to the ovulation. Thus, medications that interfere with ovulation are included both in AUB-O and AUB-I creating duplication within the PALM-COEIN classification system. Tamoxifen, corticosteroids and herbs (e.g. ginseng) are also implicated in the genesis of AUB. Abnormal uterine bleeding is relatively common with the use of anticoagulant drugs such as warfarin, unfractionated heparin, and low molecular weight heparin ${ }^{1}$.

Poorly defined and less studied entities like arteriovenous malformations and myometrial hypertrophy have been placed in a category termed "not yet classified" (AUB-N). This will accommodate any future entity as well. Functioning ovarian neoplasms (e.g. Granulosa cell tumour) can result in AUB due to endometrial hyperplasia induced by excess oestrogen secreted by the tumour. It does not seem to be appropriate to include functioning ovarian neoplasms in "not yet classified" category and it is uncertain where in the PALM-COEIN classification it should fit in.

\section{CONCLUSION}

The development of consistent and universally accepted nomenclature and standard classification system for the causes of AUB was a long-felt necessity in gynaecology. The PALMCOEIN classification was introduced as a step toward rectifying inconsistent terminologies and variably applied classification systems and it was expected to facilitate the communication, clinical care, and research among clinicians and investigators. Despite the experienced benefits, the clinical utility of PALMCOEIN classification might have been restricted by the few areas which still create some confusion. A scheduled systematic review and a substantial revision of the areas concerned will enable the PALM-COEIN classification system to become a routine in clinical practice.

\section{REFERENCES}

1. Sukhbir Singh, Carolyn Best, Sheila Dunn, et al. Abnormal Uterine Bleeding in Pre-Menopausal Women. J.Obstet.Gynaecol.Can.2013;35(5. eSuppl):S1-S28

2. Market Opinion and Research International (MORI). Women's health in 1990. [Research study conducted on behalf of Parke-Davis Laboratories]. London: MORI; 1990.

3. Frick KD, Clark MA, Steinwachs DM, et al. Financial and quality-oflife burden of dysfunctional uterine bleeding among women agreeing to obtain surgical treatment. Women's Health Issues 2009;19:70-8.

4. Woolcock JG, Critchley HO, Munro $\mathrm{MG}$, et al. Review of the confusion in current and historical terminology and definitions for disturbances of menstrual bleeding. Fertil Steril 2008;90(6):2269-80.

5. Munro MG, Critchley HO, Broder MS, Fraser IS. FIGO working group on menstrual disorders. FIGO classification system (PALMCOEIN) for causes of abnormal uterine bleeding in nongravid women of reproductive age. Int $\mathrm{J}$ Gynaecol Obstet. 2011;113:3-13. 
6. Committee on Practice BulletinsGynecology. Practice bulletin no.128: diagnosis of abnormal uterine bleeding in reproductiveaged women. Obstet Gynecol 2012; 120(1): 197-206.

7. Fraser IS, Critchley HO, Munro MG, Broder M. Can we achieve international agreement on terminologies and definitions used to describe abnormalities of menstrual bleeding? Hum Reprod 2007 Mar;22(3):635-43.

8. Munro MG, Critchley HOD, Broder MS, Fraser IS, et al. FIGO classification system (PALMCOEIN) for causes of abnormal uterine bleeding in nongravid women of reproductive age. International Journal of Gynecology and Obstetrics; 113 (2011): 3-13
9. Wamsteker K, Emanuel MH, de Kruif JH. Transcervical hysteroscopic resection of submucous fibroids for abnormal uterine bleeding: results regarding the degree of intramural extension. Obstet Gynecol 1993;82(5):736-40.

10. Lacey JV Jr, Chia VM. Endometrial hyperplasia and the risk of progression to carcinoma. Maturitas. 2009 May 20;63(1):39-44.

11. Shankar M, Lee CA, Sabin CA, et al. von Willebrand disease in women with menorrhagia: a systematic review. BJOG 2004;111(7):734-40.

12. Dilley A, Drews C, Lally C, et al. A survey of gynecologists concerning menorrhagia: perceptions of bleeding disorders as a possible cause. $J$ Womens Health Gend Based Med 2002;11(1):39-44.
13. Gleeson NC. Cyclic changes in endometrial tissue plasminogen activator and plasminogen activator inhibitor type 1 in women with normal menstruation and essential menorrhagia. Am J Obstet Gynecol 1994;171(1):178-83.

14. Smith SK, Abel MH, Kelly RW, et al. A role for prostacyclin (PGi2) in excessive menstrual bleeding. Lancet 1981;1(8219):522-4.

15. Pitsos M, Skurnick J, Heller D. Association of pathologic diagnoses with clinical findings in chronic endometritis. $J$ Reprod Med 2009;54(6):373-7. 